\title{
Monetary Union: A Welfare Based Approach ${ }^{(a)}$
}

\author{
Martine Carré ${ }^{(b)}$ \\ EPEE, Université d'Evry Val d'Essonne, and CREST \\ Fabrice Collard \\ CNRS-Cepremap
}

First draft: July 1997

This draft: July 2000

\begin{abstract}
This article aims at studying the potential benefits from implementing a monetary union. To this end, we develop a two country intertemporal general equilibrium model that extends the Obstfeld and Rogoff [1995] specification to nominal rigidities through price adjustment costs and pricing-to-market behavior.

We show that, in face of a positive asymmetric permanent shock to either technology or government expenditures occurring in one country, implementing a monetary union is beneficial to the households living in this economy. Conversely, it is detrimental to foreigners. Further, a sensitivity analysis shows that if the gains/losses to implementing monetary union are qualitatively robust in face of changes in the degree of nominal rigidities and the elasticity of substitution between foreign and domestic goods, they are quite sensitive to the degree of pricing-to-market in the economy.
\end{abstract}

Keywords: Asymmetric shocks, Flexible Exchange Rate, Monetary union, Pricing-toMarket

JEL Codes: F41, F42

\footnotetext{
${ }^{(a)}$ Part of this research was undertaken as the first author was member of EUREQua, université de Paris I and the second author benefited from the postdoctoral fellowship of the department of economics, université catholique de Louvain, Belgium. We are thankful to A. d'Autume, P. Beaudry, F. Bec, J.P. Benassy, J. Driffill, R. Farmer, S. Grégoir, J.O. Hairault, H. Hau, P.Y. Hénin, P. Kehoe, H. Kempf, P. Monfort, F. Portier, F. Postel-Vinay and J.M. Tallon. We also thank all participants to AFSE 97 congress, ESEM and EEA conferences Berlin 1998, EUI \& CEPR conference Barcelona 1998, T2M Montréal 1999, MAD, Cepremap and CREST seminars. We are also indebted to two anonymous referees for their very valuable remarks, that led to a thorough revision of a previous version of this work. All mistakes and insufficiencies are our own.

(b) Address: CREST - Laboratoire de Macroéconomie, Timbre J360, 15 BD Gabriel Peri, BP 100, 92245 Malakoff Cedex, France. Email: carre@ensae.fr
} 


\section{Introduction}

The creation of a Monetary Union in Europe is viewed as the ultimate phase of European economic and financial integration. Instituting a common currency in an highly integrated area is traditionally considered to be optimal in the sense of McKinnon [1963], as a common currency eliminates the risk associated to volatile exchange rates in international trade. Too high a misalignment would indeed distort the terms of trade among countries. However, it is often emphasized that exchange rates flexibility allows for a quicker adjustment of relative prices following asymmetric shocks when labor is not mobile, when wages are rigid or when fiscal policies are not coordinated. One is thus led back to conclude - according to the literature on optimal currency areas - that the predominance of symmetric shocks is a prerequisite for instituting a common currency.

But, the origin of the shock is also important, regardless of the degree of nominal rigidity in the economies involved in the Monetary Union. Indeed, identifying the source of the shocks (demand vs. supply) is as important as assessing their nature (symmetric vs. asymmetric) for the analysis of the desirability of a common currency. This has been underlined, among others, by Buiter [1997] in a simple model $\grave{a}$ la Dornbusch in which nominal interest rates and foreign prices are exogenous. However, this model is exposed to the usual criticism addressed to this approach, namely the lack of microeconomic foundations and the use of an $a d-h o c$ criterion (minimization of output volatility) to evaluate the desirability of exchange rate regimes. Modern international macroeconomic analysis, tracing back to Obstfeld and Rogoff [1995], permits a formal welfare evaluation of national policies — namely national monetary and budgetary shocks. In fact, Obstfeld and Rogoff's [1995] analysis has led to a new perspective on the international welfare spillovers associated to monetary and fiscal policies. Their analysis stands in contrast with more traditional models that emphasize the negative impact on domestic welfare of monetary shocks, because of "beggar-thy-neighbor" displacements of domestic aggregate demand.

This paper precisely address the issue of the consequences of the loss of exchange rate flexibility in a model that extends from Obstfeld and Rogoff [1995] in, at least, two ways.

First of all, following Corsetti and Pesenti [1998], we introduce a distinction between the degree of monopolistic competition and the elasticity of substitution between foreign and domestic goods. Indeed, as underlined by these authors, in Obstfeld and Rogoff's framework, small expansionary monetary policies - no matter where they originate - have qualitatively similar effects on national welfare levels through their impact on global consumption. Otherwise stated, welfare is a function only of global money stances, not relative money supply, as domestic and foreign goods are valued the same way by households. In this case, there is neither gain nor loss to expect from implementing monetary union. ${ }^{1}$ Departing from this assumption, we allow for qualitative and quantitative impact of relative money stances on the level of welfare and are thus able to assess the potential welfare gains/losses from monetary union. Such an evaluation has, to our knowledge, not been undertaken in this type of dynamic framework.

\footnotetext{
${ }^{1}$ It should be however stressed that this no longer holds if there are either additional sources of distortions or monetary policy rules that generate a world money supply that differs from the welfare maximizing level. In that case, a monetary union will affect welfare.
} 
Second, following Betts and Devereux [1998], we introduce price discrimination in monopolists' pricing policy and evaluate the role of "pricing-to-market" (PTM) behavior within EMU. Indeed, it has now been recognized that some results of Obstfeld and Rogoff's seminal study are closely related to the fact that the law of one price hold in their model, and that price discrimination may question their results. There is a substantial literature on the strategic determinants of international PTM behavior, beginning with the well-known contributions of Dornbusch [1987] or Krugman [1987]. ${ }^{2}$ This assumption is supported by a bunch of empirical studies that report that almost all of the short-run to medium-run volatility in real exchange rates can be attributed to failures in the law of one price, and argue that PTM plays a central role in this phenomenon (see, e.g. Betts and Devereux [1998] and Devereux and Engel [1998]). Beyond, we make the rather extreme assumption of local currency pricing, which was however found to be consistent with empirical data by many empirical studies (see, e.g. Giovannini [1988], Knetter [1993] or Feenstra and Kendall [1997]). Coupled with the observation that nominal and real exchange rates display high correlation, Devereux and Engel [1998] conclude about it that a better description of price setting can be found in imposing that nominal prices are sticky in the currency of the consumer.

We then propose a two-country intertemporal model with monopolistic competition $\grave{a}$ la Blanchard and Kiyotaki [1987] that explicitly takes the former developments into account. As aforementioned, we assume that a fraction of firms sell goods at the same price in the two countries, the law of one price (LOP) thus holds for these goods, the complementary fraction of goods is sold by firms which can discriminate prices across countries. Following Betts and Devereux [1998], the fraction of firms that adopt a PTM behavior is a parameter that can be varied. Further, we introduce nominal rigidities as it has long been recognized that, in the case of asymmetric shocks (either nominal or real), the choice of an exchange rate regime is an irrelevant question when nominal prices freely react to shocks (see Friedman [1953] or Mundell [1961]). We thus consider a smooth price adjustment, through price adjustment costs as in Hairault and Portier [1993]. This assumption allows to evaluate the impact of the degree of nominal rigidities on the desirability of monetary union. ${ }^{3}$

The setup we develop allows for capital accumulation, which provides a better understanding of the dynamics of current account (See e.g. Backus, Kehoe and Kydland [1994]). Indeed, the current account plays a crucial role in transmission of shocks in the Obstfeld and Rogoff's [1995] model. There are in fact both theoretical and empirical reasons to believe that shutting off the current account channel may lead to omit important mechanisms in the analysis of EMU. For instance, Ghironi [2000] noted that the US current account seems play an important role in generating interdependences between the US and the rest of the world. We then choose, for our purpose, to depart from the complete market assumption or the approach developed by Corsetti and Pesenti [1998], which prevents the current account to react to shocks. ${ }^{4}$ It is however worth noting that, by sticking to the original Obstfeld and

\footnotetext{
${ }^{2}$ See also Giovannini [1988] and Froot and Klemperer [1989].

${ }^{3}$ Chari, Kehoe and McGrattan [1998] also have capital accumulation and nominal rigidities but price stickiness is due to price contracts in their model. Kollmann [1996] and Betts and Devereux [1996], who also investigate the effects of sticky prices in two-country models, do not take capital accumulation into account. Beaudry and Devereux [1995] develop a two-country model, in which the price stickiness is endogenous and relies on the indeterminacy of equilibrium without price setting.

${ }^{4}$ Further, as noted by Lane [1999], the Corsetti and Pesenti solution does not accommodate PTM since
} 
Rogoff's [1995] formulation of the current account, we import the associated non-stationarity problem. Any stochastic application of our study is then precluded, and we therefore restrict our attention to the deterministic case. ${ }^{5}$ We first study the response of the economy to permanent deviations from the initial conditions and then assess the robustness of our results against temporary disturbances. In this case the importance of wealth effects is brought down and we are therefore able to provide with some intuition for what could happen when the current account channel is weakened. ${ }^{6}$

Our results clearly indicate that implementing monetary union has strong consequences on both qualitative and quantitative features of main aggregates dynamics behavior both in the short-run and in the long-run. This is in particular true for the behavior of domestic and foreign consumption and hours that determine the evolution of welfare following a technology or a fiscal shock. The analysis of the welfare properties of each exchange rate leads to clear cut results. In particular, implementing monetary union is beneficial to domestic households following a positive permanent technology or fiscal shock, whereas it is detrimental to foreign households. Sensitivity investigation shows that the gains/losses to implementing monetary union are qualitatively robust to changes in the degree of nominal rigidity and to variations in the elasticity of substitution between foreign and domestic goods. They also show that they are sensitive to the degree of PTM in the economy. In particular, switching from a high to a low degree of PTM revert the results: winners become losers.

The paper proceeds as follows. The setup of the model is described in a first section. A second section is devoted to the calibration of the model. In a third section we study the impact of non-anticipated asymmetric shocks on the dynamics of some aggregates in both institutional settings, thus allowing for a comparison between the flexible exchange rates regime and the common currency regime. The performance of the different regimes in terms of welfare are assessed in a fourth section. A last section offers some concluding remarks.

\section{The model}

The world economy is comprised of a continuum of agents split between two countries, each of them being of unit mass. There is a continuum of goods.

\subsection{The households}

Domestic and foreign households are infinitely lived and assumed to be identical, such that we consider the problem of a representative agent. This representative agent decides consumption, savings and hours plans maximizing the discounted flow of instantaneous utilities

$$
U_{t}=\sum_{s=t}^{\infty} \beta^{s-t} \frac{\left(c_{s}^{\nu}\left(1-h_{s}\right)^{1-\nu}\right)^{1-\sigma}-1}{1-\sigma}
$$

home and foreign price levels are then disentangled.

${ }^{5}$ Moreover, from a pure technical point of view, we have to be aware that our experiments depend of the choice of our choice of initial conditions and the steady state around which the system is approximated. Nevertheless, in the experiments we will conduct, we will never be far away from the initial position.

${ }^{6}$ Very recent work by Ghironi [2000] focuses on the non-stationarity problem, and proposes a solution that does not shut-off the current account channel by assuming that new agents, endowed with no financial assets, are born in each and every period. 
where $\beta \in(0,1)$ denotes the discount factor, $h_{t}$ denotes hours worked during period $t$ and $c_{t}$ is the bundle of goods consumed by the representative household at time $t:^{7}$

$$
c_{t}=\left[\omega^{\frac{1}{\rho}} c_{t}^{\frac{\rho-1}{\rho}}+(1-\omega)^{\frac{1}{\rho}} c_{t}^{\frac{\rho-1}{\rho}}\right]^{\frac{\rho}{\rho-1}}
$$

where $\rho>0$ is the elasticity of substitution between $c_{t}^{h}$ and $c_{t}^{f}$, respectively the basket of goods produced in the domestic and the foreign economy, and $\omega \in[0,1]$ is the share of the domestic bundle in the consumption goods basket. $c_{t}^{h}$ and $c_{t}^{f}$ are given by:

$$
c_{t}^{h}=\left(\int_{0}^{1} c_{t}(h)^{\frac{\theta-1}{\theta}} \mathrm{d} h\right)^{\frac{\theta}{\theta-1}} \text { and } c_{t}^{f}=\left(\int_{0}^{1} c_{t}(f)^{\frac{\theta-1}{\theta}} \mathrm{d} f\right)^{\frac{\theta}{\theta-1}}
$$

where $\theta>0$ is the elasticity of substitution between the goods. It will turn out that it determines the markup of price over marginal cost. Hence, as in Corsetti and Pesenti [1998], this model introduces a discrepancy between the markup over marginal cost and the elasticity of substitution between foreign and domestic goods. The goods are of two kinds: (i) goods which price is different in the two countries, $c_{t}^{m}(i), i \in[0, s]$, introducing a PTM mechanism in the model and (ii) goods which are priced the same way in the two countries, $c_{t}^{a}(i), i \in[s, 1]$ for which LOP holds. The domestic demands for domestic and foreign goods are then given by:

$$
\begin{array}{lll}
\text { Domestic PTM good } & : & c_{t}^{m}(h)=\left(\frac{p_{t}^{m}(h)}{p_{t}}\right)^{-\theta}\left(\frac{p_{t}^{h}}{p_{t}}\right)^{\theta-\rho} \omega c_{t} \\
\text { Domestic LOP good } & : & c_{t}^{a}(h)=\left(\frac{p_{t}^{a}(h)}{p_{t}}\right)^{-\theta}\left(\frac{p_{t}^{h}}{p_{t}}\right)^{\theta-\rho} \omega c_{t} \\
\text { Foreign PTM good } & : & c_{t}^{m}(f)=\left(\frac{p_{t}^{m}(f)}{p_{t}}\right)^{-\theta}\left(\frac{p_{t}^{f}}{p_{t}}\right)^{\theta-\rho}(1-\omega) c_{t} \\
\text { Foreign LOP good } & : & c_{t}^{a}(f)=\left(\frac{e_{t} p_{t}^{a \star}(f)}{p_{t}}\right)^{-\theta}\left(\frac{p_{t}^{f}}{p_{t}}\right)^{\theta-\rho}(1-\omega) c_{t}
\end{array}
$$

where $p_{t}, p_{t}^{h}$ and $p_{t}^{f}$ are prices aggregates given by: ${ }^{8}$

$$
p_{t}=\left(\omega p_{t}^{h^{1-\rho}}+(1-\omega) p_{t}^{f^{1-\rho}}\right)^{\frac{1}{1-\rho}}
$$

\footnotetext{
${ }^{7}$ This index will be symmetric in the foreign country :

$$
c_{t}^{\star}=\left(\omega^{\frac{1}{\rho}} x_{t}^{f \star \frac{\rho-1}{\rho}}+(1-\omega)^{\frac{1}{\rho}} x_{t}^{h \star \frac{\rho-1}{\rho}}\right)^{\frac{\rho}{\rho-1}}
$$

${ }^{8}$ The corresponding price aggregate in the foreign economy are given by:

$$
\begin{aligned}
p_{t}^{\star} & =\left((1-\omega) p_{t}^{h \star 1-\rho}+\omega p_{t}^{f \star 1-\rho}\right)^{\frac{1}{1-\rho}} \\
p_{t}^{h \star} & =\left(\int_{0}^{s} p_{t}^{m \star}(h)^{1-\theta} \mathrm{d} h+\int_{s}^{1}\left(\frac{p_{t}^{a}(h)}{e_{t}}\right)^{1-\theta} \mathrm{d} h\right)^{\frac{1}{1-\theta}} \\
p_{t}^{f \star} & =\left(\int_{0}^{s} p_{t}^{m \star}(f)^{1-\theta} \mathrm{d} f+\int_{s}^{1} p_{t}^{a \star}(f)^{1-\theta} \mathrm{d} f\right)^{\frac{1}{1-\theta}}
\end{aligned}
$$
}




$$
\begin{aligned}
p_{t}^{h} & =\left(\int_{0}^{s} p_{t}^{m}(h)^{1-\theta} \mathrm{d} h+\int_{s}^{1} p_{t}^{a}(h)^{1-\theta} \mathrm{d} h\right)^{\frac{1}{1-\theta}} \\
p_{t}^{f} & =\left(\int_{0}^{s} p_{t}^{m}(f)^{1-\theta} \mathrm{d} f+\int_{s}^{1} e_{t} p_{t}^{a \star}(f)^{1-\theta} \mathrm{d} f\right)^{\frac{1}{1-\theta}}
\end{aligned}
$$

where $e_{t}$ is the nominal exchange rate. It is worth noting here that the consumption and the price indexes are somehow biased in favor of the goods produced in the country where consumer resides. This actually reflects the empirical findings on the composition of the consumption baskets. Most of the goods consumed by the households belonging to one economy is mostly composed of goods produced in this economy (see e.g. Backus, Kehoe and Kydland [1995]). As a consequence, consumption-based PPP never holds in the model.

Each household receives payments for hours she provides on the labor market, $p_{t} w_{t} h_{t}$ where $w_{t}$ denotes the real wage, and earns $p_{t} r_{t} k_{t}$ from renting capital to firms, $r_{t}$ is the real rental rate and $k_{t}$ is the physical capital stock. The latter evolves as:

$$
k_{t+1}=\Psi\left(\frac{i_{t}}{k_{t}}\right) k_{t}+(1-\delta) k_{t}
$$

where $0 \leq \delta \leq 1$ denotes the rate of depreciation, and $i_{t}$ is investment. ${ }^{9}$ The increasing and concave function $\Psi($.$) reflects the presence of adjustment costs to investment. It is assumed$ to be twice differentiable and homogeneous of degree 0 . Further we impose two additional assumptions that guarantee the absence of adjustment costs in the steady state: $\Psi(\delta)=\delta$ and $\Psi^{\prime}(\delta)=1$.

The household also receives profits, $\Pi_{t}$. The net income is used first on financial and money markets (i) to trade a bond, whose holding is denoted $f_{t}$, at price $R_{t}$ and (ii) to get cash, $M_{t}$, which will be used on the good market to purchase consumption and investment goods and pay taxes. The household then faces the following cash-in-advance constraint: ${ }^{10}$

$$
M_{t} \geqslant p_{t}\left(c_{t}+i_{t}+T_{t}\right)
$$

and, the budget constraint is given by: ${ }^{11}$

$$
M_{t}+R_{t} f_{t+1} \leqslant f_{t}+p_{t} w_{t} h_{t}+p_{t} r_{t} k_{t}+\Pi_{t}
$$

\footnotetext{
${ }^{9}$ Investment is a bundle of goods of the same form as the consumption bundle, in order to avoid demand composition effects.

${ }^{10}$ Note that following Obstfeld and Rogoff [1996], our specification does not require a household to hold foreign currency, even if his/her country is running a current account deficit. This implicitly amounts to assume that the household does not face any conversion costs, or, in others, to assume that both currencies are highly liquid, which seems to be a reasonable assumption.

${ }^{11}$ Note that the only asset is a nominal bond denominated in home country currency units. An implication of this assumption is that asymmetric shocks will affect the international distribution of wealth through current account effects. Another interesting alternative have been proposed by Corsetti and Pesenti [1998] and Obstfeld and Rogoff [1998] who deliberately abstract from current account adjustment and focus directly on the terms of trade transmission mechanism. However, the assumption of perfect international risk pooling precludes discussions on wealth redistributions between countries, which would underestimate the gains/losses associated to an exchange rate regime switching.
} 
We therefore assume that domestic agents are the sole owners of domestic firms, and symmetrically that foreign agents are the sole owners of foreign firms. This assumption rules out the possibility of a mutualization of risk across households of different nationalities.

The problem of the domestic household is then to maximize (1) subject to (4)-(6). Similar assumptions are put on the foreign household. ${ }^{12}$

\subsection{Government and monetary authorities}

In each and every period, the government purchases a bundle of goods, $g_{t} \cdot{ }^{13}$ Since Ricardian equivalence holds in this model, we can assume without loss of generality that there is no public debt. The government budget constraint is hence simply given by:

$$
g_{t}=T_{t}
$$

Finally, money supply in each country follows the simple rule:

$$
M_{t}=g_{M} M_{t-1}
$$

where $g_{M}-1$ is the constant rate of growth of money. Note that, in the sequel, $g_{M}$ will be set to 1 , such that money stances will be constant. This very simple rule is intended to capture the idea that monetary policy is used to guarantee prices stability, which is explicitly mentioned as a major objective of German, French and Spanish central banks among others. This price objective remains the main goal of the ECB. ${ }^{14}$

Implementing EMU will amounts, in this setting, to create a central bank of the union, which supplies the overall money of the union, $\bar{M}_{t}$, according to the simple rule:

$$
\bar{M}_{t}=\bar{g}_{M} \bar{M}_{t-1}
$$

where $\bar{g}_{M}-1$ is the constant rate of growth of money in the union. The money market equilibrium is then given by:

$$
\bar{M}_{t}=M_{t}+M_{t}^{\star}
$$

\subsection{Firms}

Firms interact strategically, determining the price and the demand of factor of production taking aggregate output and aggregate demand as given. The good market is therefore characterized by a monopolistic competition à la Blanchard and Kiyotaki [1987]. As aforementioned, there exist two pricing behaviors. A share $s \in[0,1]$ of monopolists can charge different prices in the two countries and adopt a PTM behavior. The complementary share $(1-s)$ charges the same price in the two countries and are subjected to the LOP.

\footnotetext{
${ }^{12}$ Hereafter, foreign variables are denoted by a $\star$.

${ }^{13}$ Likewise $i_{t}$ this bundle has the same composition as the consumption bundle.

${ }^{14}$ Other monetary policies may be implemented to achieve this goal such as the so-called Taylor rules that used the nominal interest rate as the monetary instrument (see e.g. Loyo [1997], Ball [1999] or Collard and Dellas [2000] for Taylor rules in an open economy framework).
} 


\subsubsection{LOP goods producers}

Each LOP domestic firm $h \in[s, 1]$ produces a good $h$ with a constant returns to scale technology:

$$
y_{t}^{a}(h)=a_{t} k_{t}^{a}(h)^{\alpha} h_{t}^{a}(h)^{1-\alpha}
$$

where $k_{t}^{a}(h)$ and $h_{t}^{a}(h)$ denote respectively the capital stock of firm $h$ and hours worked in that firm at time $t$. $a_{t}$ is a technological factor common to all domestic firms. ${ }^{15}$

Following Hairault and Portier [1993], we assume that it is costly for firms to change their price - thus introducing a nominal rigidity — and that there exists a price adjustment cost function $\Phi\left(\frac{p_{t}^{a}(h)}{p_{t-1}^{a}(h)}\right)$ increasing and convex with respect to changes in the pricing policy. We further assume that $\Phi(1)=\Phi^{\prime}(1)=0$, such that there are no adjustment costs in steady state $^{16}$. We thus assume that only deviations of the growth rate of prices from its value at the steady state are costly. Finally, firms' adjustment costs are expressed in terms of the domestic composite consumption good. ${ }^{17}$

Each firm determines the level of capital and hours, and the price it will charge so as to maximize its discounted flow of profits. The presence of adjustment costs on prices makes the problem of a firm explicitly dynamic. It solves the following problem:

$$
\max \sum_{t=0}^{\infty} R_{t}\left[p_{t}^{a}(h) y_{t}^{a}(h)-p_{t}\left(w_{t} h_{t}^{a}(h)+r_{t} k_{t}^{a}(h)+\Phi\left(\frac{p_{t}^{a}(h)}{p_{t-1}^{a}(h)}\right)\right)\right]
$$

subject to

$$
y_{t}^{a}(h) \leqslant \mathcal{Y}_{t}^{a}(h)
$$

$\mathcal{Y}_{t}^{a}(h)=c_{t}^{a}(h)+i_{t}^{a}(h)+g_{t}^{a}(h)+\Phi_{t}^{a}(h)$ represents the demand addressed to LOP firm $h$, which is given by:

$$
\mathcal{Y}_{t}^{a}(h)=\left(\frac{p_{t}^{a}(f)}{p_{t}}\right)^{-\theta} y_{t}^{w}
$$

where $y_{t}^{w}$ is a world demand aggregate given by:

$$
y_{t}^{w}=\omega\left(\frac{p_{t}^{h}}{p_{t}}\right)^{\theta-\rho} y_{t}+(1-\omega)\left(\frac{p_{t}^{f^{\star}}}{p_{t}^{\star}}\right)^{\theta-\rho} y_{t}^{\star}
$$

where $y_{t}$ and $y_{t}^{\star}$ are aggregate domestic and foreign demand.

\subsection{PTM goods producers}

Each PTM firm $h \in[0, s]$ produces a good $h$ with a constant returns technology:

$$
a_{t} k_{t}^{m}(h)^{\alpha} h_{t}^{m}(h)^{1-\alpha}
$$

where $k_{t}^{m}(h)$ and $h_{t}^{m}(h)$ denote, as before, the capital stock of firm $h$ and hours worked in that firm at time $t .^{18}$

\footnotetext{
${ }^{15}$ The specification of the LOP firms' technology in the foreign country is similar, although it does not experiment the same technological factor $\left(a_{t}^{\star}\right)$.

${ }^{16}$ Note that implicit in this formulation is that we consider a zero inflation rate in steady state.

${ }^{17}$ They are expressed in terms of the foreign composite good in the foreign economy.

${ }^{18}$ The form of the technology of PTM firms in the foreign country is identical, although it does not experiment the same technological factor $\left(a_{t}^{\star}\right)$.
} 
Contrary to LOP firms, PTM firms can discriminate between the domestic and the foreign country. They will thus charge different prices depending on the location of demand. However, like LOP firms, PTM firms face price adjustment costs. The costs apply to both prices, so that there is an adjustment cost function for each price:

$$
\Phi\left(\frac{p_{t}^{m}(h)}{p_{t-1}^{m}(h)}\right) \text { and } \Phi\left(\frac{p_{t}^{m \star}(h)}{p_{t-1}^{m \star}(h)}\right)
$$

For sakes of simplicity, we assume that these costs take the same form as for LOP firms.

As previously, each PTM firm determines the level of capital and hours, and the prices it will charge so as to maximize its discounted flow of profits:

$$
\begin{gathered}
\max \sum_{t=0}^{\infty} R_{t}\left[p_{t}^{m}(h) y_{t}^{m}(h)+p_{t}^{m \star}(h) y_{t}^{m \star}(h)-p_{t}\left(w_{t} h_{t}^{m}(h)+r_{t} k_{t}^{m}(h)\right.\right. \\
\left.\left.+\Phi\left(\frac{p_{t}^{m}(h)}{p_{t-1}^{m}(h)}\right)+\Phi\left(\frac{p_{t}^{m \star}(h)}{p_{t-1}^{m \star}(h)}\right)\right)\right]
\end{gathered}
$$

subject to

$$
\begin{aligned}
& y_{t}^{m}(h) \leqslant \mathcal{Y}_{t}^{m}(h) \\
& y_{t}^{m \star}(h) \leqslant \mathcal{Y}_{t}^{m^{\star}}(h) \\
& a_{t} k_{t}^{m}(h)^{\alpha} h_{t}^{m}(h)^{1-\alpha} \leqslant y_{t}^{m}(h)+y_{t}^{m \star}(h)
\end{aligned}
$$

where $\mathcal{Y}_{t}^{m}(h)=\left(\frac{p_{t}^{m}(h)}{p_{t}}\right)^{-\theta}\left(\frac{p_{t}^{h}}{p_{t}}\right)^{\theta-\rho} \omega y_{t}$ and $\mathcal{Y}_{t}^{m^{\star}}(h)=\left(\frac{p_{t}^{m \star}(h)}{p_{t}^{\star}}\right)^{-\theta}\left(\frac{p_{t}^{h \star}}{p_{t}^{\star}}\right)^{\theta-\rho}(1-\omega) y_{t}^{\star}$.

\subsection{Equilibrium}

We focus on the symmetric equilibrium, at which all LOP (PTM) producers of a given country charge the same price:

$$
\begin{aligned}
& p_{t}^{a}(i)=p_{t}^{a}(h), \forall i \in(s, 1) \text { and } p_{t}^{m}(i)=p_{t}^{m}(h), p_{t}^{m \star}(i)=p_{t}^{m \star}(h) \forall i \in(0, s) \\
& y_{t}^{a}(i)=y_{t}^{a}(h), \forall i \in(s, 1) \text { and } y_{t}^{m}(i)=y_{t}^{m}(h), y_{t}^{m \star}(i)=y_{t}^{m \star}(h) \forall i \in(0, s)
\end{aligned}
$$

in the home country and

$$
\begin{aligned}
& p_{t}^{a \star}(i)=p_{t}^{a \star}(f), \forall i \in(s, 1) \text { and } p_{t}^{m}(i)=p_{t}^{m}(f), p_{t}^{m \star}(i)=p_{t}^{m \star}(f) \forall i \in(0, s) \\
& y_{t}^{a \star}(i)=y_{t}^{a \star}(f), \forall i \in(s, 1) \text { and } y_{t}^{m}(i)=y_{t}^{m}(f), y_{t}^{m \star}(i)=y_{t}^{m \star}(f) \forall i \in(0, s)
\end{aligned}
$$

in the foreign country. At the symmetric equilibrium, the goods price indices are therefore equal to:

$$
\begin{aligned}
& p_{t}^{h}=\left(s p_{t}^{m}(h)^{1-\theta}+(1-s) p_{t}^{a}(h)^{1-\theta}\right)^{\frac{1}{1-\theta}} \\
& p_{t}^{f}=\left(s p_{t}^{m}(f)^{1-\theta}+(1-s)\left(e_{t} p_{t}^{a \star}(f)\right)^{1-\theta}\right)^{\frac{1}{1-\theta}} \\
& p_{t}^{h \star}=\left(s p_{t}^{m \star}(h)^{1-\theta}+(1-s)\left(\frac{p_{t}^{a}(h)}{e_{t}}\right)^{1-\theta}\right)^{\frac{1}{1-\theta}} \\
& p_{t}^{f \star}=\left(s p_{t}^{m \star}(f)^{1-\theta}+(1-s) p_{t}^{a \star}(f)^{1-\theta}\right)^{\frac{1}{1-\theta}}
\end{aligned}
$$


An equilibrium of this economy is a set of prices

$$
\mathcal{P}_{t}=\left\{p_{t}, p_{t}^{\star}, p_{t}^{a}(h), p_{t}^{m}(h), p_{t}^{m \star}(h), p_{t}^{a \star}(f), p_{t}^{m}(f), p_{t}^{m \star}(f), w_{t}, w_{t}^{\star}, r_{t}, r_{t}^{\star}, R_{t}, e_{t}\right\}_{t=0}^{\infty}
$$

and the sets of quantities

$$
\begin{aligned}
& \mathcal{Q}_{t}=\left\{c_{t}, c_{t}^{\star}, i_{t}, i_{t}^{\star}, k_{t+1}, k_{t+1}^{\star}, f_{t+1}, f_{t+1}^{\star}, h_{t}, h_{t}^{\star}\right\}_{t=0}^{\infty} \\
& \mathcal{Y}_{t}(h)=\left\{h_{t}^{a}(h), h_{t}^{m}(h), k_{t}^{a}(h), k_{t}^{m}(h), y_{t}^{a}(h), y_{t}^{m}(h), y_{t}^{m \star}(h)\right\}_{t=0}^{\infty} \\
& \mathcal{Y}_{t}^{\star}(f)=\left\{h_{t}^{a \star}(f), h_{t}^{m \star}(f), k_{t}^{a \star}(f), k_{t}^{m \star}(f), y_{t}^{a \star}(f), y_{t}^{m}(f), y_{t}^{m_{\star}}(f)\right\}_{t=0}^{\infty}
\end{aligned}
$$

such that:

1. Given the set of prices $\mathcal{P}_{t}$, the set of quantities $\mathcal{Q}_{t}$ maximizes domestic and foreign households' utility;

2. Given the set of prices $\mathcal{P}_{t}$, the sets of quantities $\mathcal{Y}_{t}(h), \mathcal{Y}_{t}^{\star}(f)$ maximizes domestic and foreign firms' profit;

3. Given the sets of quantities $\mathcal{Q}_{t}, \mathcal{Y}_{t}(h), \mathcal{Y}_{t}^{\star}(f)$, the set of prices $\mathcal{P}_{t}$ clears all markets in the sense:

$$
\begin{array}{rll}
h_{t}=s h_{t}^{m}(h)+(1-s) h_{t}^{a}(h) & \text { and } & h_{t}^{\star}=s h_{t}^{m \star}(f)+(1-s) h_{t}^{a \star}(f) \\
k_{t}=s k_{t}^{m}(h)+(1-s) k_{t}^{a}(h) & \text { and } & k_{t}^{\star}=s k_{t}^{m \star}(f)+(1-s) k_{t}^{a \star}(f) \\
y_{t}^{a}(h)=\mathcal{Y}_{t}^{a}(f) & \text { and } & y_{t}^{m}(h)=\mathcal{Y}_{t}^{m}(h)+\mathcal{Y}_{t}^{m \star}(h) \\
y_{t}^{a \star}(f)=\mathcal{Y}_{t}^{a \star}(f) & \text { and } & y_{t}^{m \star}(f)=\mathcal{Y}_{t}^{m}(f)+\mathcal{Y}_{t}^{m \star}(f)
\end{array}
$$

together with

$$
\begin{aligned}
& y_{t}=c_{t}+i_{t}+g_{t}+s\left(\Phi_{t}^{m}(h)+\Phi_{t}^{m \star}(h)\right)+(1-s) \Phi_{t}^{a}(h) \\
& y_{t}^{\star}=c_{t}^{\star}+i_{t}^{\star}+g_{t}^{\star}+s\left(\Phi_{t}^{m}(f)+\Phi_{t}^{m \star}(f)\right)+(1-s) \Phi_{t}^{a \star}(f) \\
& 0=f_{t}+e_{t} f_{t}^{\star}
\end{aligned}
$$

\section{Calibration}

The dynamic system describing the general equilibrium of this economy does not admit an analytical solution. We thus rely on a numerical approach and therefore need a calibration of the deep parameters of the model this section describes.

We assume that the economies are symmetric. In particular, we follow Obstfeld and Rogoff [1995] and assume that in initial position the worldwide wealth is equally distributed across the two economies, such that all aggregates are at the same level in the two economies. Further, in this initial position, holdings of international bonds are set to zero.

The model is calibrated for a benchmark European economy, namely the French economy, relying heavily on previous work by Hairault and Portier [1993]. We assume, without loss of generality, that the economies display neither growth nor inflation in the steady state. 
The labor share in output is set to its mean value on French national account, 54\%. The markup rate is arbitrarily set to 0.225 , value used by Hairault and Portier [1993]. ${ }^{19}$ Given that at the steady state, the markup rate is $1 /(\theta-1)$ we get $\theta=5.4444$. Then, $\alpha$ is set such that the labor share in output equals its empirical counterpart. $\rho$, the elasticity of substitution between domestic and foreign goods, is set to 1.5 as a benchmark value, referring to the work by Backus, Kehoe and Kydland [1992]. However a sensitivity analysis will be conducted on this parameter. $\omega$ the preference for domestic goods is set such that the model matches the french import share $(22.5 \%)$.

$\delta$, the depreciation rate for physical capital is set such that the annual depreciation is $5 \%$. The parameter $\psi$, the elasticity of the marginal capital adjustment cost, is set to $-0.05 .{ }^{20} \phi$, elasticity of the marginal price adjustment cost - the parameter determining the degree of nominal rigidities - is set to 25 . This value was selected such that the model yields roughly the same persistence of exchange rate as the one exhibited by Chari et al. [1998]. This value is given only for benchmark considerations, as we will undertake a sensitivity analysis in order to assess the sensitivity of our results to nominal rigidities. $\sigma$, ruling the intertemporal elasticity of substitution, is set to 2.5. $\nu$ is such that an individual devotes $35 \%$ of its total time endowment to productive activities. $\beta$, the discount factor, is such that the households discounts the future at a $3 \%$ yearly rate.

Finally, $s$ remains to be set. Knetter [1993] reports estimates of the proportion of industries that are subject to "local-currency price stability" in several countries. This is essentially equivalent to PTM in our model. His point estimates differ sensitively across countries. We then chose to follow Chari et al. [1998] and retain — as a benchmark - a situation where all firms adopt a pricing-to-market behavior (namely $s=1$ ). In others, our benchmark will be a situation in which the law of one price does not hold at all and where there is complete local currency pricing. This latter assumption has some empirical support (see, e.g. Giovannini [1988], Marston [1990] and Knetter [1993] or Feenstra and Kendall [1997]). For instance, Engel and Rogers [1999] show that most of the failures of the law of one price across European cities over the period 1981-1997 can be mostly attributed to local currency pricing. In order to assess the robustness of our results against the degree of PTM, we will undertake a sensitivity analysis to parameter $s$.

\section{Asymmetric shocks and aggregate dynamics}

This section is devoted to the analysis of the aggregate adjustment dynamics of the two economies following an unanticipated permanent change ${ }^{21}$ in the level of technology $(a)$ and government expenditures $(G)$. Changes only occur in the domestic economy.

\footnotetext{
${ }^{19}$ Hairault and Portier [1993] argue that the French economy is less competitive than the US economy for which the markup is 0.197 according to Morrison [1994].

${ }^{20}$ In this case, a stochastic version of the model, assuming complete asset markets, matches the relative volatility of investment in the french economy. However, a sensitivity analysis, available from the authors upon request, shows that the results are not qualitatively affected by changes in $\psi$.

${ }^{21}$ Note that in our experiments, the initial condition is set such that wealth is equally distributed over the two economies.
} 


\subsection{Domestic Technology shock}

We consider a $1 \%$ permanent increase in domestic technology. As we assume there is no international correlation in the technology, this shock is totally asymmetric in the sense it only occurs in the home economy. Impulse response functions of the domestic and foreign aggregates are reported in figures 1 and 2.

Figure 1: Technology shock
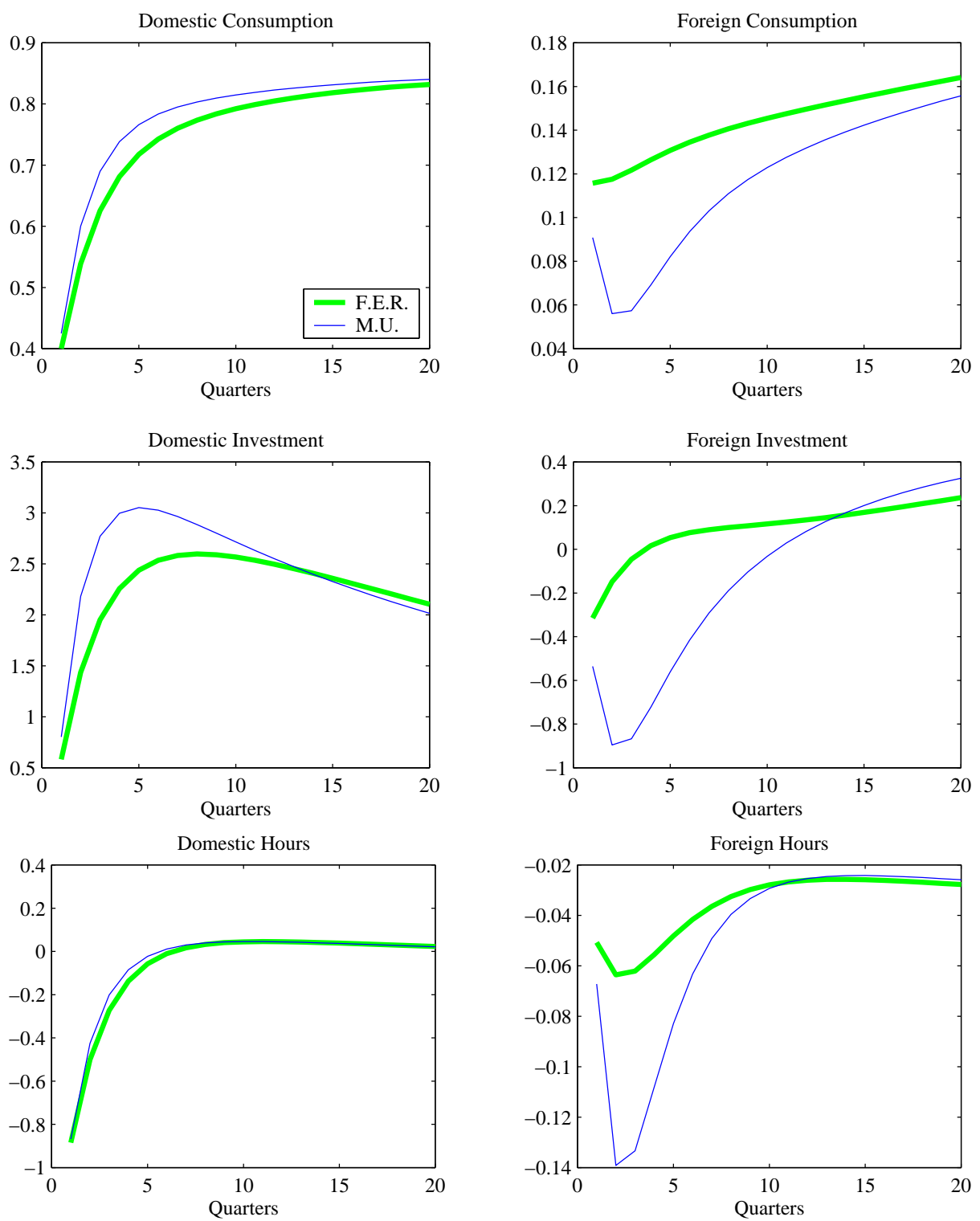

Under both flexible exchange rate regime and EMU, the aggregate dynamics in the domestic economy is essentially driven by two mechanisms. The first one refers to the standard intertemporal substitution motive that is associated to the increase in the real interest rate, following the positive technology shock. By pushing up the real interest rate, this creates an incentive for households to accumulate at a greater pace. The second one refers to the stan- 
Figure 2: Technology shock
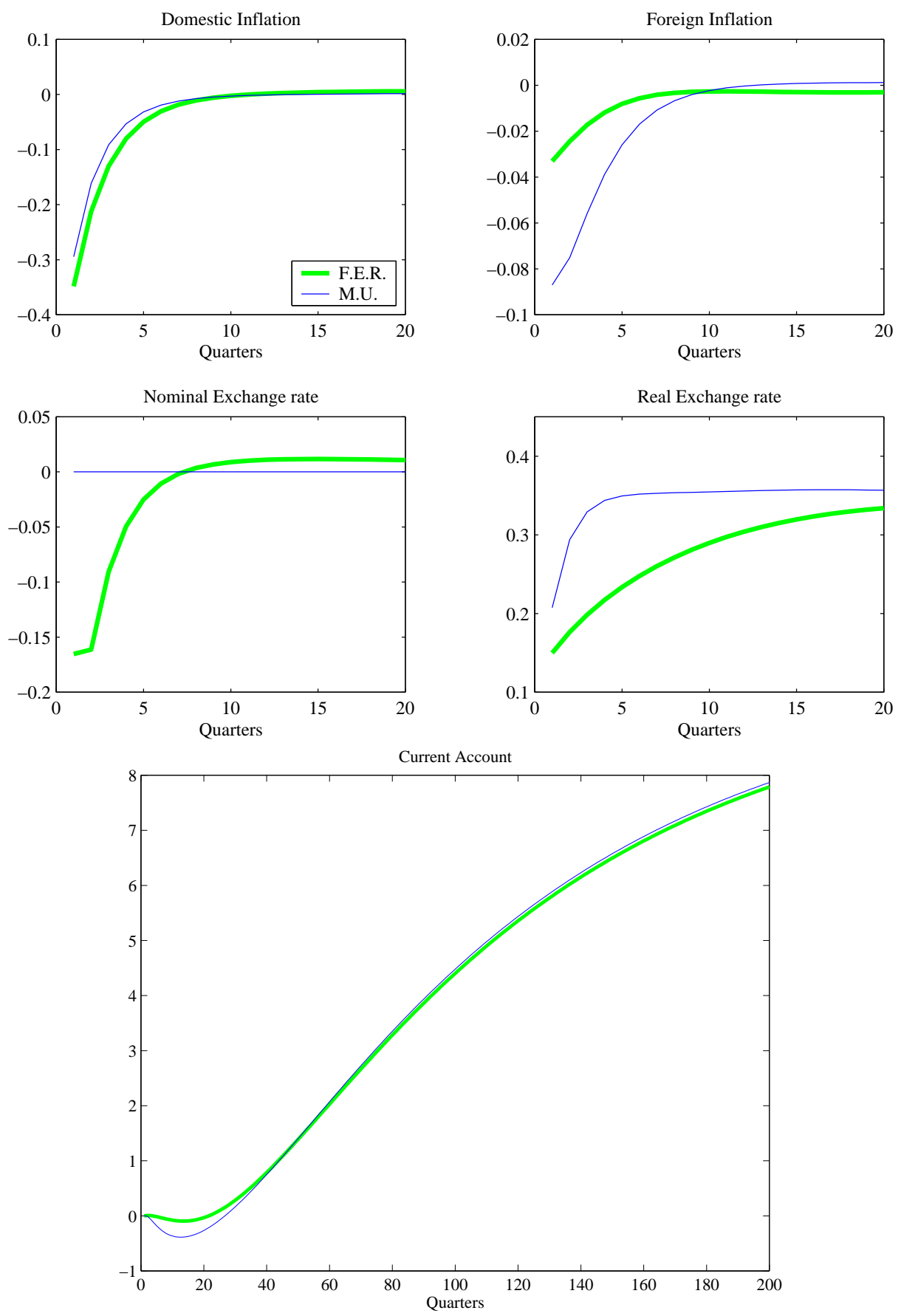
dard positive wealth effect associated to an increase in the level of technology, that pushes output up in the domestic economy and therefore increases - Ceteris Paribus - both the income and the wealth of the representative household in the domestic economy. This phenomenon is illustrated, for instance, by the increase in the current account, which essentially constitutes the financial wealth of the representative household in the economy (See lower panel in figure 2). It is noteworthy that as this shock is taken to be permanent, this positive wealth effect fully operates.

These two mechanisms have standard implications in the domestic economy. In the shortrun, consumption rises since the household's permanent income is above its steady state level (see figure 1). This increase in aggregate domestic consumption also takes place in the long run since the positive wealth effect is permanent. ${ }^{22}$ The wealth effect together with the rise in the marginal productivity of capital leads the household to accumulate capital at a greater pace, such that investment rises above its steady state value. Two forces are driving the dynamics of total hours worked in the economy. On the one hand, intratemporal substitution motives associated to the increase in current real wages (following the increase in marginal productivity of labor) together with intertemporal substitution motives associated to the increase in real interest rate (following the increase in marginal productivity of capital) make it profitable for the household to increase her labor supply. On the other hand, as the household is wealthier, she can achieve the same level of consumption without increasing her labor supply. Since the wealth effect is permanent in our model economy, the latter mechanism dominates — as shown in Hansen [1997]. This implies that the household decreases her labor supply in equilibrium. A direct implication of the latter result is that the marginal return of capital decreases, thus lowering the incentive to invest and therefore explaining the long-run decrease in domestic investment.

The evolution of both consumption and hours work towards an increase in the domestic welfare in the domestic economy.

In a standard manner, the positive supply shock yields a nominal appreciation of the domestic currency under the flexible exchange rate regime (see figure 2). Indeed, the cash in advance constraint implies that domestic households increase their demand for money in order to purchase the additional amount of goods demanded for consumption and investment purposes. $^{23}$ Conversely, despite the appreciation of the nominal exchange rate, the real exchange rate rises, indicating a real depreciation of the domestic currency. This actually reflects the decrease in all prices in the domestic economy, but also, to a lesser extent a decrease in the prices charged by foreign firms (see upper panel in figure 2). Indeed, as supply is above its steady state, market clearing imposes that domestic firms charge lower prices in both the domestic and the foreign economy. ${ }^{24}$ As domestic firms also sell on the foreign market, they compete with foreign firms. Competition puts downward pressure on prices charged by foreign firms in the foreign economy. In others, the decrease in the domestic

\footnotetext{
${ }^{22}$ It is worth noting that even in face of a stationary supply shock, the rise in household's income would have been permanent as the assumption on the structure of asset markets implies that any deviation in the current account permanently affects the wealth cross-country distribution.

${ }^{23} \mathrm{It}$ is important to note that although this result may appear to be specific to our modeling of the demand for money, it remains robust to another specification such as money in the utility function or shopping time.

${ }^{24}$ It is however worth noting that since prices are not perfectly flexible, part of the adjustment is achieved rising the markup rate.
} 
inflation rate is partly accounted for by lower prices charged by foreign firms in the domestic economy.

The imported deflation together with the real depreciation of the domestic currency mainly explains the aggregate dynamics in the foreign economy. Indeed, as the aggregate price level decreases in the foreign economy, foreign households are more inclined to consume. This impact effect is reinforced by the permanent feature of this imported deflation. Therefore, consumption purchases increase in the foreign economy. Nevertheless, the rise in consumption is less pronounced in the foreign economy than in the domestic $(0.11 \%$ in the foreign economy to be compared to $0.40 \%$ in the domestic economy under a flexible exchange rate regime). Two phenomena may provide an explanation to this result. First of all, even if the decrease in the aggregate price level generates, Ceteris Paribus, a positive income effect in the foreign economy, it is not as strong as in the domestic economy since the former does not benefit from the direct positive effect of the technology shock. Second, the foreign economy suffers from a lack of competitiveness vis à vis the domestic economy, which tends to put downward pressure on the demand for foreign goods, thus leading firms to slow down their demand for labor - which dampens to an even greater extent the positive income effect associated to the lowering in aggregate prices. The decrease in the labor demand translates into a relative lowering of labor in equilibrium, which lowers the marginal productivity of capital and therefore yields foreign individuals to invest less. All this implies that, in the short-run, welfare tends to rise above its steady state value in the foreign economy, but to a lesser extent than in the domestic economy.

In the longer-run, and as suggested in the upper right panel of figure 2, the positive income effect associated to the decrease in the aggregate price index decreases. Further, the real exchange rate remains in favor of the domestic economy, such that demand addressed to foreign firms is still depressed. Therefore, firms keep on demanding less labor in the longer run. This together with the sustained higher consumption implies that foreign households are still better off in the longer run, and like in the short-run to a lesser extent than domestic individuals.

Although all we stated above mostly applies under both the flexible exchange rate regime and EMU, differences arise between the two regimes. As should be expected, most of the differences are to be found in the behavior of prices, and more precisely in the real exchange rate. Indeed, under the flexible exchange rate regime, the nominal exchange rate acts as an automatic stabilizer for the evolution of the real exchange rate. This obviously disappears under EMU. Therefore, as can be seen from the lower right panel of figure 2, the response of the real exchange rate is magnified, yielding a stronger purchasing power effect. This has an important consequence in the domestic economy as, by magnifying the demand for domestic good (by a competitiveness effect), it increases the labor demand in the domestic economy. This induces an intratemporal substitution effect from leisure toward consumption, that tends to magnifies the response of consumption. Hence we are left with two effects that play in opposite direction on the welfare. Nevertheless, the consumption effect takes the upper hand (see upper and lower left panels of figure 1) for our benchmark calibration. In others, domestic households are better off in a monetary union compared to a flexible exchange rate regime.

The implications of EMU on foreign households are even more clear cut as the real ex- 
change rate was found to be the main mechanism driving the response of aggregates (essentially consumption and hours worked) in the foreign economy. The first important implication of EMU, as far as the foreign economy is concerned, is to magnify the decrease in the foreign inflation rate, since the nominal exchange rate does not absorb the domestic positive technological shock anymore. An important implication of this is that it yields a lower response of consumption in the foreign economy relative to the flexible exchange rate. Indeed, as the magnitude of the real exchange rate response is higher, the foreign economy is relatively less competitive than under a flexible exchange rate regime. This puts downward pressure on the demand addressed to the foreign economy and discourages labor. This magnifies the response of leisure and lowers the overall income effect such that foreign consumption responds to a much lesser extent.

We thus end up with a configuration where leisure rises by a greater amount, whereas consumption is smoother. The net effect on foreign welfare is therefore undetermined. Nevertheless, for our calibration, the consumption effect is more important, such that foreign individuals are worse off under EMU. In order to evaluate the robustness of the latter result, a sensitive analysis will be undertaken in section 4 .

\section{Domestic Fiscal Shock}

We now investigate the implications of a $1 \%$ permanent rise in government expenditures. Like technology shocks, we assume there is no international correlation in government expenditures, so that this shock is asymmetric. Impulse response functions of domestic and foreign aggregates are reported in figures 3 and 4 .

A permanent increase in government expenditures yields, Ceteris Paribus, an instantaneous increase in the overall demand in both economy. Therefore, as prices are not perfectly flexible in the short-run, domestic output has to temporarily shift upward in order to clear the good market. This demand side effect is reinforced by a supply side effects associated to the standard negative wealth effect implied by a higher lump-sum tax. Indeed, as government levies higher taxes to finance its consumption expenditures, it creates a strong negative wealth effect, illustrated by the decrease in the current account in the domestic economy (see lower panel of figure 4). Then, domestic households have to raise permanently their labor supply in order to maintain their permanent income and smooth consumption. This reinforces the initial increase in domestic output as each domestic producer benefits from the increase in labor availability. A second implication of the aforementioned negative wealth effect is a standard crowding out effect that depresses both domestic and consumption and investment in the short-run. As the increase in government expenditures is permanent, this drop in consumption persists in the longer-run. This, together with the permanent decline in domestic leisure $^{25}$ implies that domestic households are worse off following a positive permanent fiscal shock, although output is higher.

Further - because of the cash-in-advance constraint - the rise in domestic demand translates into an increase in the demand for domestic money. This has two main implications. First of all and whatever the exchange rate regime we consider, domestic inflation passes below

\footnotetext{
${ }^{25}$ As the negative wealth effect is permanent, domestic households permanently increase their labor supply. Otherwise stated, leisure is permanently lower.
} 
Figure 3: Fiscal shock
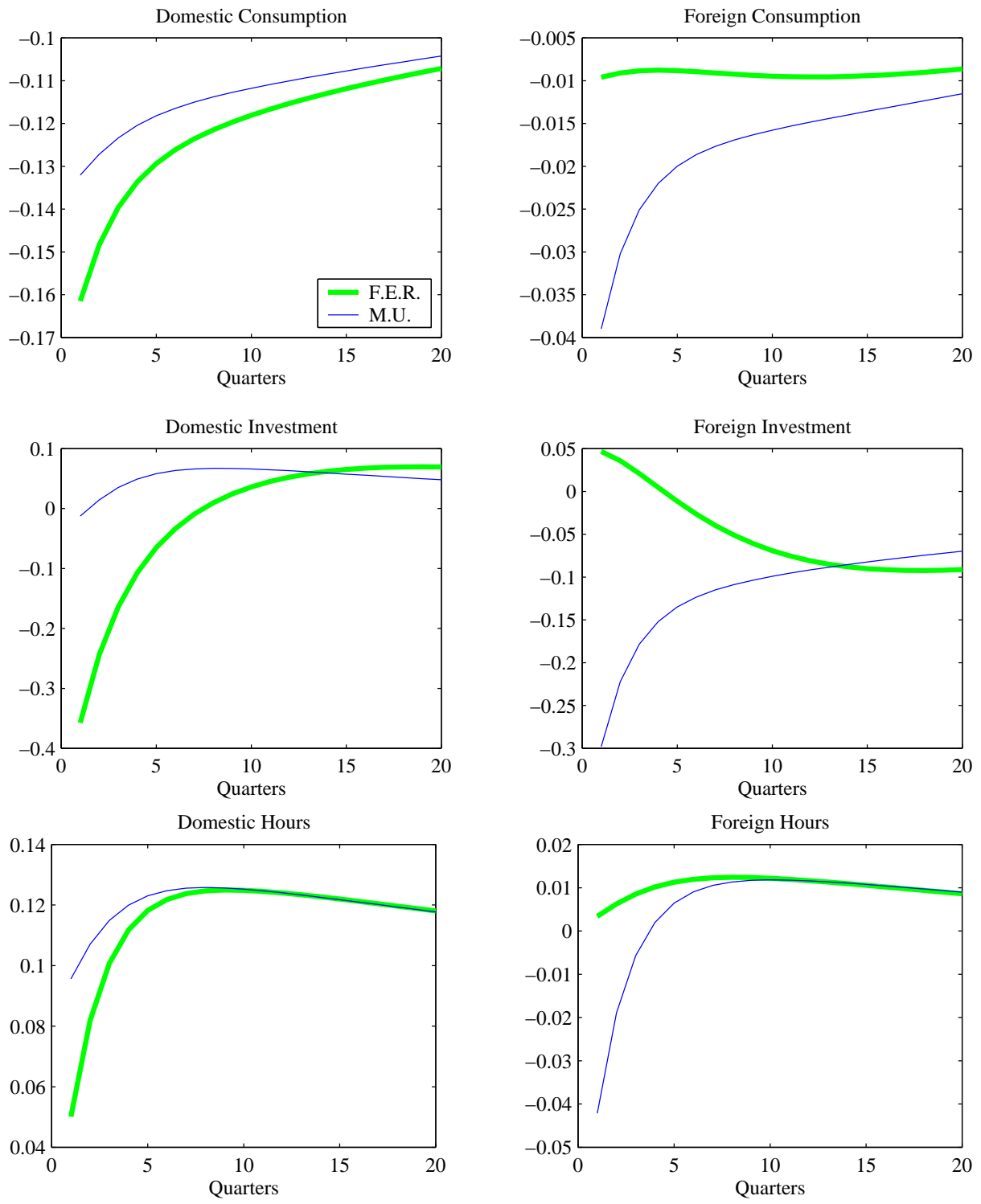
Figure 4: Fiscal shock
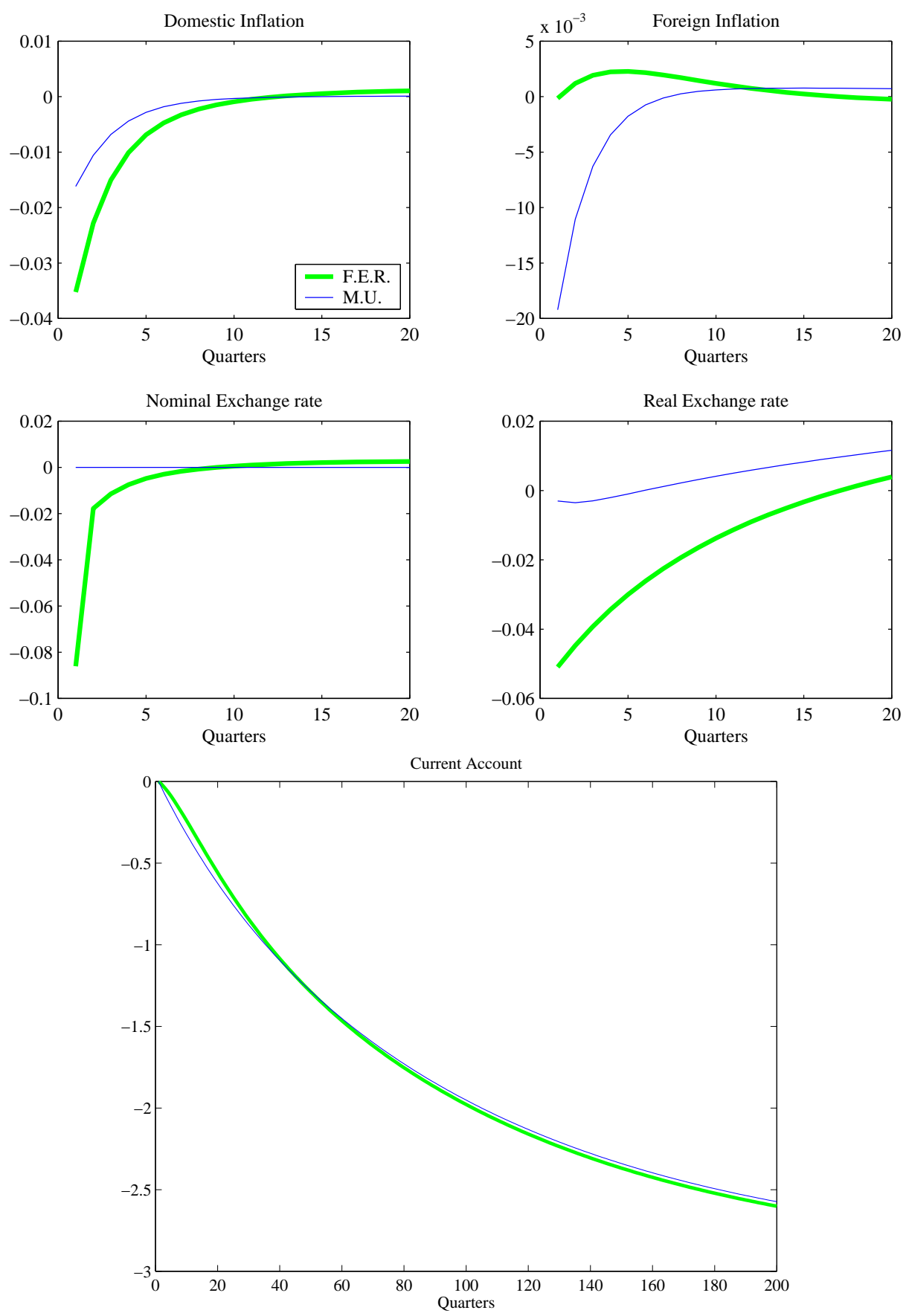
its steady state value (as can be deduced from equation 5). Second of all, under a flexible exchange rate regime, the domestic currency appreciates. ${ }^{26}$ Things are more complicated in terms of real exchange rate. Indeed, on the one hand, and as already mentioned by Obstfeld and Rogoff [1995], the relative rise in domestic output plays in favor of an appreciation of the domestic currency. On the other hand, the appreciation of the domestic currency puts downward pressure on the real exchange rate and thus acts in the opposite direction. In our model, because of the specification of the money demand, the latter effect takes the upper hand, such that the real exchange rate drops.

These price effects together with the permanent wealth effect reflected in the evolution of the current account are at the core of the response of aggregates in the foreign economy. As far as hours worked are concerned, the positive wealth effect related to the improvement in the current account in the foreign economy puts downward pressure on hours worked, as the analysis of the response to a technology shock has already shown. But, the appreciation of the domestic currency translates into a price competitiveness effect that plays in favor of the goods produced in the foreign economy. In others, foreign goods are more demanded following a domestic fiscal shock, ${ }^{27}$ encouraging labor in the foreign economy. In a flexible exchange rate regime, these two competing effects almost cancel out. Nevertheless, the total outcome is a tiny increase in foreign hours worked in the very short-run, which persists in the longer-run due to the permanence of the shock. The behavior of foreign consumption is more tricky. Indeed, on the one hand, the aforementioned positive wealth effect plays in favor of an increase in consumption. But, on the other hand, the increase in the real interest rate $^{28}$ creates an incentive for foreign households to postpone consumption (by an intertemporal substitution phenomenon). The latter mechanism takes the upper hand and foreign consumption drops. Hence, the decrease in consumption together with the increase in hours worked - i.e. a drop in leisure - implies that foreign households are globally worse off following a permanent domestic fiscal shock.

The move to EMU modifies both the qualitative and quantitative features of aggregate dynamics in both economy. Like in the case of the technology shock, the main difference in the adjustment dynamics may be found in the dynamics of prices, due to the abandonment of the flexible nominal exchange rate. Since in a monetary union, there is no more nominal exchange rate adjustment, the real exchange rate diminishes by a lesser extent, although the drop in foreign inflation is more pronounced. This implies that, all things being equal, the foreign economy benefits from a lower competitiveness effect than under the flexible exchange rate regime. Therefore, the demand addressed to domestic firms is greater in EMU, encouraging employment in the domestic economy. Then, this latter effect reinforces the magnitude of the

\footnotetext{
${ }^{26}$ The results generated by our model mainly differ from Obstfeld and Rogoff [1995] in their implications for the exchange rate. In Obstfeld and Rogoff [1995], money enters the utility function directly. Demand for money then positively depends on the level of domestic consumption, and negatively on real interest rate. Thus, a decrease in domestic consumption leads to a decrease in demand for domestic money, which therefore depreciates. Chang and Lai [1997] also show how sensitive the response of exchange rate is with respect to the specification of demand for money.

${ }^{27}$ It is worth stressing that most of this increase in demand addressed to the foreign economy is directly related to the demand stemming solely from domestic government purchases.

${ }^{28}$ The foreign real interest rate instantaneously increases by $0.0323 \%$ in face a $1 \%$ permanent fiscal shock in the domestic economy as the domestic economy demands more funds from the foreign economy.
} 
response of hours worked (see lower left panel of figure 3). This exerts a positive income effect, as for a given real wage the labor income increases to a greater extent, which counters the negative wealth effect associated to the domestic fiscal shock. Thus, domestic consumption drops by less than under a flexible exchange rate regime. This yields two competing effects on the domestic household's welfare. On the one hand, the lower drop in consumption tends to improve the situation of the domestic household relative to the flexible exchange rate regime. On the other hand, the larger increase in hours worked makes her worse off. For our calibration, as the next section will show, the move to EMU implies that the welfare loss is lower than under a flexible exchange rate regime. However, welfare is quite sensitive to the parameterization of the model economy.

The implementation of the monetary union also affects the foreign household's behavior. Both foreign consumption and hours worked drop by a much greater extent than under flexible exchange rate regime. The explanation of this result can be found in the adjustment dynamics of the real exchange rate. As aforementioned, the abandonment of the nominal exchange rate flexibility generates a much lower real exchange rate depreciation, such that the foreign economy looses much of its competitiveness relative to the domestic economy. ${ }^{29}$ Therefore, the demand addressed to the foreign economy is lower, discouraging foreign employment. This implies that, all things being equal, the foreign household faces a lower labor income relative to the flexible exchange rate regime, which puts downward pressure on foreign consumption (see upper right panel of figure 3). In the longer run, prices recover their flexibility and the difference between the two regimes solely originates in the accumulation of the initial wealth transfer. This underlines the key role of the current account in our analysis. Shutting off the current accounts would have broken this mechanism enabling us to distinguish between the two exchange rate regimes in the long run. Then, like for the domestic economy, two competing effects affect the welfare on the foreign agents. On the one hand, the larger decrease in consumption tends to make foreign households worse off, while the larger increase in leisure makes them better off. The former effect takes the upper hand for our benchmark calibration, so that EMU is detrimental to foreign households, as shown in the next section.

This clearly illustrates how monetary union affects the qualitative and quantitative features of both the domestic and foreign economies in both the short-run and the long-run. This is especially true for hours and consumption, which essentially determine the level of welfare reached by households in both economy. It is then natural to address the question of gains and losses following an asymmetric shock from a normative point of view and pursue a sensitivity analysis of our results to changes in the deep parameters.

\section{A Normative Analysis of the Monetary Union}

This section first describes the criterion we use to evaluate the potential gain to monetary union, and then presents results obtained for our benchmark calibration. We then undertake a sensitivity analysis of our results to assess the robustness of the desirability of EMU.

\footnotetext{
${ }^{29}$ Note that this effect is magnified when PTM vanishes (when $s \longrightarrow 0$ ), PTM being a way to avoid the switch away pertaining to the competitive effect.
} 


\subsection{A welfare criterion}

As the model provides with a fully micro-founded utility criterion, we build on a welfare analysis. Like Lucas [1987] — in the case of the welfare cost of fluctuations - we express the welfare gains (losses) to monetary union in readily interpretable economic terms: The gain to monetary union is then given by the permanent transfer rate on consumption an individual should be given in order to compensate the fact that she has to bear a flexible exchange rate regime rather than a monetary union. Let $x$ denote this transfer rate. It is given by:

$$
\sum_{t=0}^{\infty} \beta^{t} u\left((1+x) c_{t}^{F}, 1-h_{t}^{F}\right)=\sum_{t=0}^{\infty} \beta^{t} u\left(c_{t}^{M U}, 1-h_{t}^{M U}\right)
$$

where $F$ and $M U$ respectively stand for flexible exchange rate regime and monetary union.

It should be clear to the reader that as soon as $x$ is positive, the household prefers the monetary union. Indeed, when $x>0$, consumption under flexible exchange rate must be raised in order to yield the same utility as under a monetary union. In other words, the household has to be given permanently extra consumption in order to compensate for the loss in utility under a flexible exchange rate regime compared to a monetary union. For example, a $1 \%$ positive transfer rate means that consumption under flexible exchange rates must be raised by $1 \%$ in each and every period in order to yield the same level of welfare as under a monetary union. Otherwise stated, welfare is higher under monetary union.

\subsection{Results}

A first result that stands out from our model is that EMU is beneficial to domestic households following either a positive technology or fiscal shock. For instance, following a 1\% permanent domestic technology (fiscal) shock, domestic households should be given a $0.38 \%(0.14 \%)$ permanent rise in consumption ${ }^{30}$ in order to compensate for the loss in utility under a flexible exchange rate regime compared to monetary union. Conversely, foreign households lose out to the institution of monetary union when a positive shock occurs in the domestic country. For instance, following a $1 \%$ permanent domestic technology (fiscal) shock domestic households should be taken away a $0.8 \%(0.11 \%)$ of permanent consumption ${ }^{31}$ to compensate for the gains in utility under a flexible exchange rate regime compared to monetary union.

As previously shown by the IRF analysis, following a technology shock, the nominal exchange rate acts as a real exchange rate stabilizer under a flexible exchange rate regime. This translates into a stabilization of wealth transfer between the two countries (as can be seen from the weaker overall response of the current account to a technology shock under a flexible exchange rate regime, figure 2), which may be viewed as an insurance mechanism between the two countries. Therefore, the wealth effect associated to the technology shock is smoothed under a flexible exchange rate regime. On the contrary, this is no more the case under a monetary union, such that domestic households consume more. Further, as prices are rigid, the labor supply has to rise in order to satisfy the supplementary demand for domestic goods that results from (i) the direct wealth effect of the domestic positive

\footnotetext{
${ }^{30}$ This roughly corresponds to 2 free lunches in a fast-food restaurant per quarter.

${ }^{31}$ This roughly corresponds to 2 lunches in a fast-food restaurant and 2 movies lost per quarter and the evening is wasted.
} 
technology shock and (ii) the switch away from foreign goods toward domestic goods due to the competitiveness effect. We thus have two effects that play in opposite direction. On the one hand, the potential increase in consumption leads domestic households to prefer monetary union. On the other hand, the additional demand for labor under monetary union leads them to loose in terms of welfare. For our calibration, the consumption gain dominates and domestic households fare better under a monetary union regime.

As far as the fiscal shock is concerned, we find the same opposite effects on welfare. Under a flexible exchange rate, the dynamics of nominal exchange rate amplifies the real exchange rate in face of a positive fiscal shock. The implied appreciation of domestic money then deteriorates the home goods competitiveness. This triggers a switch away from domestic towards foreign goods, which leads the domestic households to work relatively less under a flexible exchange rate regime than under a monetary union. The negative wealth effect associated to taxes is then magnified (as can be seen from the larger response of the current account in the medium run under the flexible exchange rate regime (figure 4)). Therefore, domestic individuals consume relatively less under flexible than under EMU. For our calibration, and because of the key role we assign to wealth transfer phenomena in this model, the latter effect takes the upper hand and domestic households prefer monetary union. ${ }^{32}$

We now undertake a sensitivity analysis of our results to variations in the degree of PTM. Figure 5 reports results for a values of $s$ ranging from 0 (no pricing-to-market behavior) to 1 (full pricing-to-market behavior, our benchmark showcase).

It first appears that whatever the shock we consider, the results are very sensitive to a variation of $s$. Domestic households seem to benefit more from the move to EMU as pricingto-market behavior dominates. Conversely, foreign households are more and more worse off under EMU than under flexible exchange rate regime as $s$ rises. In order to understand this result, it is important to note that as in Devereux and Engel [1998] our model has essentially two major sources of inefficiencies, as far as exchange rate dynamics is concerned: (i) the price stickiness and (ii) the fact that consumers in different locations pay different prices for the same good (PTM), even if, as in our model, transportation costs are zero. In particular, (ii) implies that an exchange rate appreciation has little effect on the relative price of imported goods facing by domestic or foreign consumers. PTM therefore reduces the classic "expenditure switching" effects of exchange rate appreciation, which conventionally induces a shift in world demand towards exports of the country whose currency weakens (See Betts and Devereux [1998]).

In order to provide with a better understanding of the effects of change in the degree of PTM, we first set $s$ to 0 , such that we shut off the second source of inefficiency and only the first inefficiency stemming from price rigidity matters. In this case, the law of one price holds

\footnotetext{
${ }^{32}$ This result is actually closely related to our money demand modeling. Using a standard cash-in-advance constraint $\left(M_{t}=p_{t} c_{t}\right)$, domestic money would depreciate following a fiscal shock. Then, the results in terms of welfare would be reversed: monetary union would be detrimental to domestic households in face of a positive fiscal shock. Results are robust in face of a technology shock.
} 
Figure 5: Degree of PTM: $s$

Technology shock
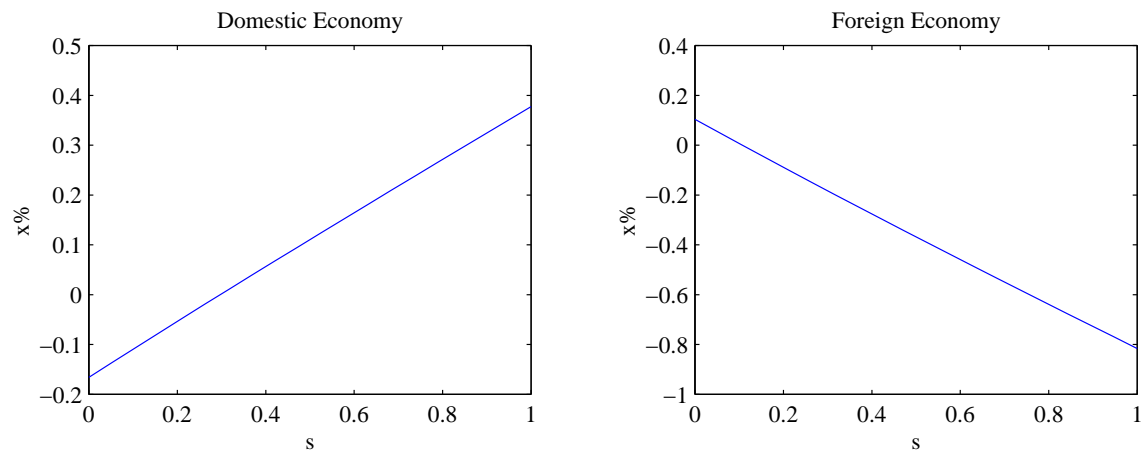

Fiscal shock
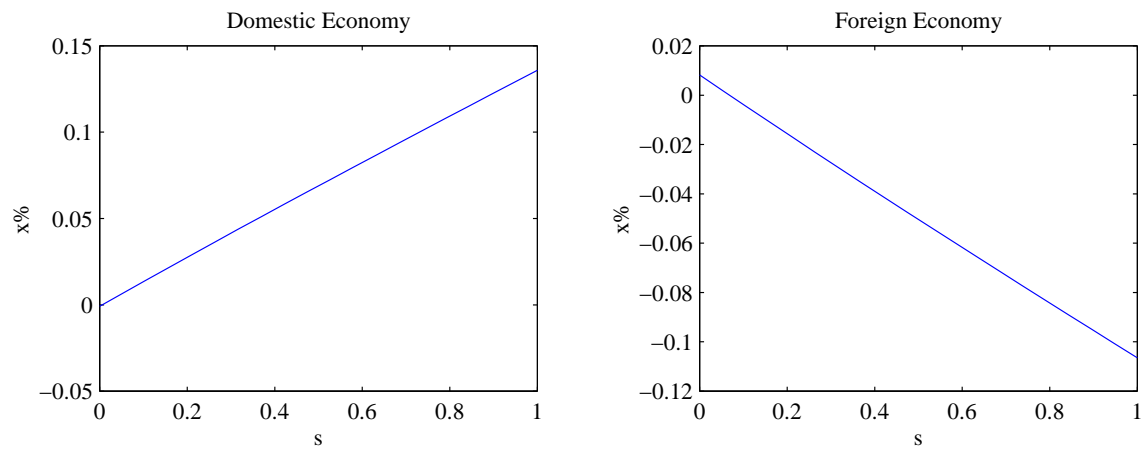

for each good. Nevertheless, as consumption-based price index then reduces to

$$
\begin{aligned}
& p_{t}=\left(\omega p_{t}^{a}(h)^{1-\rho}+(1-\omega)\left(e_{t} p_{t}^{a \star}(f)\right)^{1-\rho}\right)^{\frac{1}{1-\rho}} \\
& p_{t}^{\star}=\left(\omega p_{t}^{a \star}(f)^{1-\rho}+(1-\omega)\left(p_{t}^{a}(h) / e_{t}\right)^{1-\rho}\right)^{\frac{1}{1-\rho}}
\end{aligned}
$$

PPP still does not hold since the consumption basket is not symmetric between the two countries. Under a flexible exchange rate regime and with $s=0$, the nominal exchange rate can fully exerts its traditional stabilizing effect on the real exchange rate (see the previous section), and counters the inefficiency arising from the price rigidity. Therefore, the domestic household will be able to take a greater advantage from the positive technology shock under a flexible exchange rate regime. On the contrary, under a monetary union, the nominal exchange rate regime is no more there to counter the inefficiency resulting from the price rigidity, such that the household cannot fully enjoy the rise in technology in terms of consumption and leisure. In other words, the domestic household will be better off under a flexible exchange rate regime than under a monetary union, when the LOP fully holds. Conversely, because the real exchange rate effect plays the over way around for her, the foreign household can take advantage of the situation and she is better off under EMU compared to her situation under flexible exchange rate regime. In fact, the lower $s$ is, the smoother the deterioration in the terms of trade is under a flexible exchange rate regime relative to a monetary union (where this effect does not play).

Under total pricing-to-market $(s=1)$, which corresponds to our benchmark case, the 
two sources of inefficiency are present. Nevertheless, as consumption-based price indexes rewrite as

$$
\begin{aligned}
& p_{t}=\left(\omega p_{t}^{m}(h)^{1-\rho}+(1-\omega) p_{t}^{m}(f)^{1-\rho}\right)^{\frac{1}{1-\rho}} \\
& p_{t}^{\star}=\left(\omega p_{t}^{m \star}(f)^{1-\rho}+(1-\omega) p_{t}^{m \star}(h)^{1-\rho}\right)^{\frac{1}{1-\rho}}
\end{aligned}
$$

the stabilizing role of nominal exchange rate does not play as much as in the previous case for the domestic economy. Nevertheless, nominal exchange rate fluctuations can still lead to severe misalignment of goods prices across countries, as underlined by Devereux and Engel [1998]. Under a monetary union, the elimination of nominal exchange rate fluctuations implies that the law of one price holds good per good as far as production prices are concerned (see e.g. Benigno [1999a]). Therefore, monetary union eliminates the second inefficiency and domestic households are better off, while foreign households, who benefited from the inefficiency, are worse off. But, it is worth noting that welfare losses from failures of the LOP are not totally eliminated under monetary union, as, if they disappear in terms of production price index, they do not as far as consumption-based price index is concerned because of the own country bias in the consumption basket. Further, the inefficiency stemming from price stickiness remains since, as shown by Devereux and Engel [1998] and Engel and Rogers [1999], increase swings in the world income occur when nominal exchange rate fluctuations are eliminated. ${ }^{33}$ In particular, this implies that, as the impulse response function analysis as shown, the domestic household will be more responsive in terms of consumption under EMU, yielding to a greater welfare gain.

As expected, from the latter discussion, the greater the size of PTM behavior is, the larger are the welfare gains from EMU. As far as the technology shock is concerned, situations with a low PTM $(s<0.3)$ give rise to welfare losses in the domestic economy when EMU is implemented, whereas strong PTM yields welfare gains. Conversely, while the foreign households were better off under EMU when $s<0.3$, they become worse off for a high degree of PTM. In other words, winners become losers. It is however worth noting that many empirical studies support the view of local currency pricing. In particular, using a data set on consumer prices from 55 locations across 11 European countries, Engel and Rogers [1999] show that local currency pricing is an important phenomenon to account for border effects in Europe. This suggests, for instance, that in face of a positive technological shock arising in one country, this country will gain from implementing EMU.

Similar phenomena are at work in the case of a fiscal shock, and the same shape can be observed in the evolution of welfare gains/losses from moving to a single currency world. Nevertheless, the potential welfare gains and losses are of much lower magnitude in the case of the fiscal shock. This can mainly be attributed to the way fiscal shocks are introduced in the model. They do not create any distortion and satisfy the Ricardian equivalence principle, such that they exert a much smaller role that technology shocks. ${ }^{34}$ It is however interesting to note that as the LOP holds $(s \rightarrow 0)$ the welfare gains from EMU tend to 0 in the domestic

\footnotetext{
${ }^{33}$ Note that this shows, how our choice of not shutting off the current account can be crucial to generate our results.

${ }^{34}$ Our results are in accordance with the RBC literature that has shown that fiscal shock, modeled as nonproductive government expenditures do not play a great role in the aggregate dynamics of an economy. This is also in accordance with the econometric literature that has shown, using VAR models, that government expenditures shocks account for a small share of total output volatility.
} 
economy.

We now examine the effects of variations in the the elasticity of substitution between domestic and foreign goods,$\rho$. It is worth noting that this experiment is undertaken in our benchmark calibration, where the degree of PTM is set to 1. It appears that as $\rho$ increases monetary union becomes more and more beneficial to the domestic economy (see figure 6). Indeed, in a fully specialized world, the more the goods are substitutable, the more the shocks are perceived to be asymmetric, and the more the exchange rate regime matters. As households have clear preferences for monetary union in our benchmark situation, increases in $\rho$ just reinforce this phenomenon. Note that as $\rho \rightarrow 1$, we recover the Corsetti

Figure 6: Variations in $\rho$

Technology shock
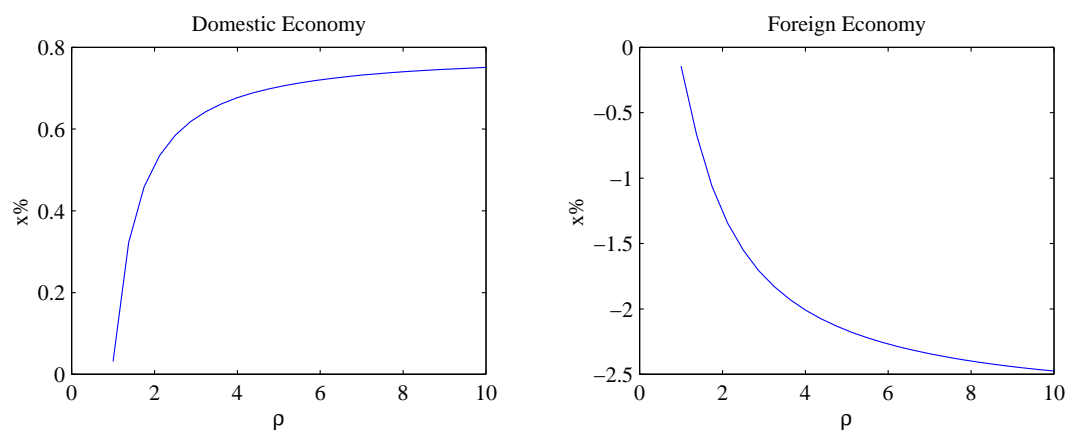

Fiscal shock
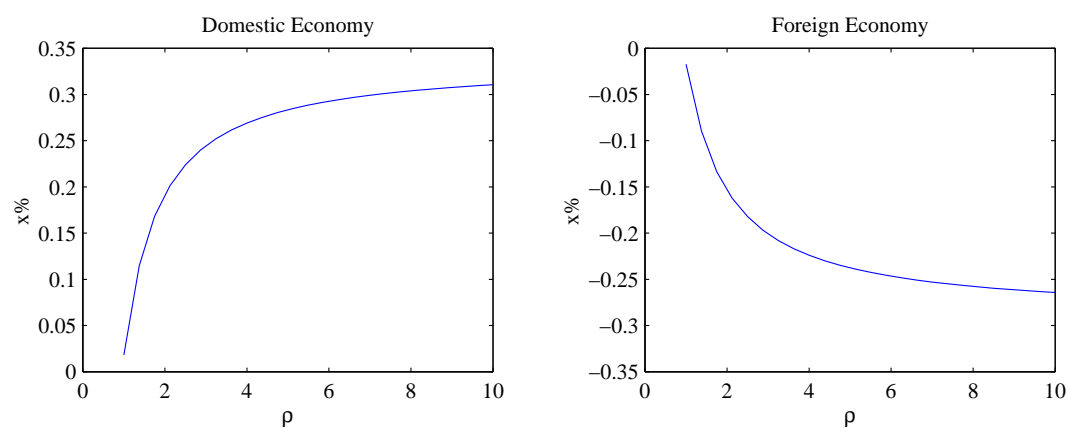

and Pesenti's (1998) assumption of a unitary elasticity of substitution between foreign and domestic goods. In this limit case, our result indicate that no gains nor losses should be expected from implementing EMU. This result actually highlights the key role of the current account channel, and more precisely international swings in wealth, as a mechanism that creates a major difference across exchange rate regimes, following the modification in the real exchange rate behavior.

We now have a look to the effects of the nominal rigidity on the potential gains to monetary union. Results are reported in figure 7, where we graph the transfer rate, $x$, as a function of the degree of nominal rigidities, $\varphi$. Like the previous experiment, this is conducted assuming that firms are able to fully discriminate between countries, such that $s=1$. Further, changes 
in the degree of nominal rigidity are assumed to be effective throughout the world economy. ${ }^{35}$ Our results indicate that the higher $\varphi$ is, the higher is the gain to monetary union as EMU contributes to the weakening of the inefficiency arising precisely from price stickiness. Our results are in accordance with Friedman [1953], Mundell [1961] or, more recently, Buiter's [1997] argument that establishes the neutrality of the exchange rate regime in the absence of nominal rigidities in this type of model. Then, as expected, the exchange rate regime matters and higher nominal rigidities lead to value monetary union in the domestic economy. This result contrasts with the conventional wisdom that higher nominal rigidities lead to prefer flexible exchange rates, which accommodate asymmetric shocks. Hence, using a welfare based criteria allows to challenge the conventional wisdom which is based on ad hoc criteria involving output and/or prices volatilities.

Figure 7: Degree of nominal rigidity: $\varphi$

Technology shock
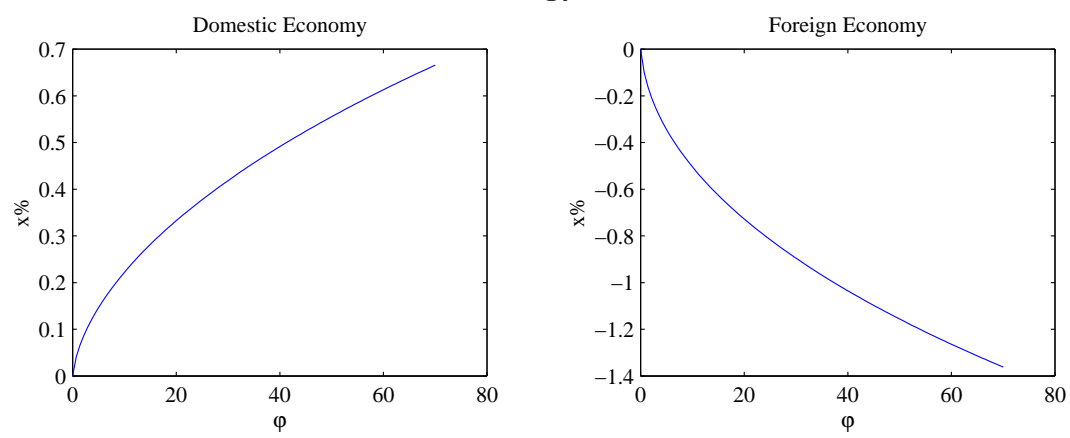

Fiscal shock
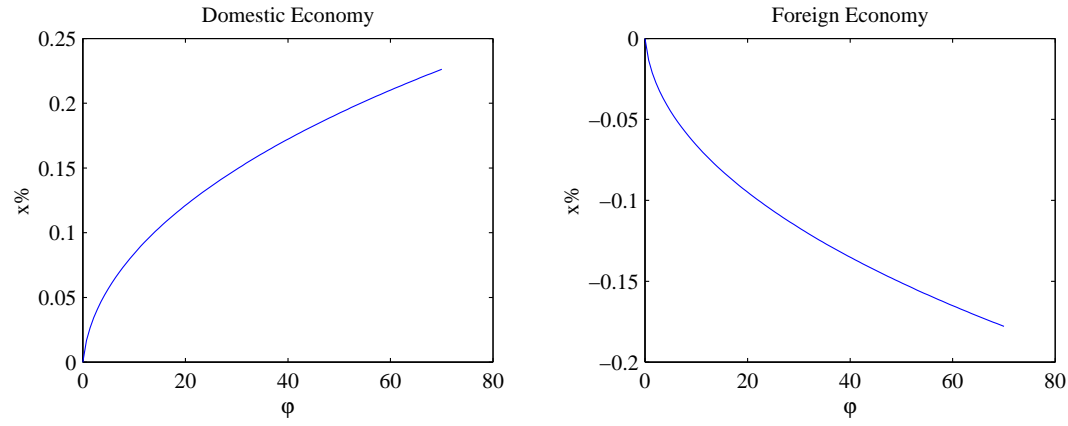

As a last experiment, we also perform a sensitivity analysis of the welfare gains/losses to EMU to the persistence parameter of the shocks. As widely known (see e.g. King, Plosser and Rebelo [1988]), the lower the persistence of the shocks is, the greater is the role of intertemporal substitution effects in the propagation of the shocks. Hence, this experiment allows to assess the role of the wealth effect, transiting through the current account, for our results and assess their robustness.

\footnotetext{
${ }^{35}$ Along the lines of Benigno [1999b], we also perform an experiment where we let the degree of nominal rigidity vary in the domestic economy, and hold it constant in the foreign economy. The results are then qualitatively equivalent, the higher the degree of nominal rigidity in the domestic economy, the higher are the gains to EMU in the domestic economy, and the more the foreign households loose. The gains are however quantitatively smaller as less can be gained.
} 
Figure 8: Persistence of the shocks: $\rho_{a}, \rho_{g}$

Technology shock
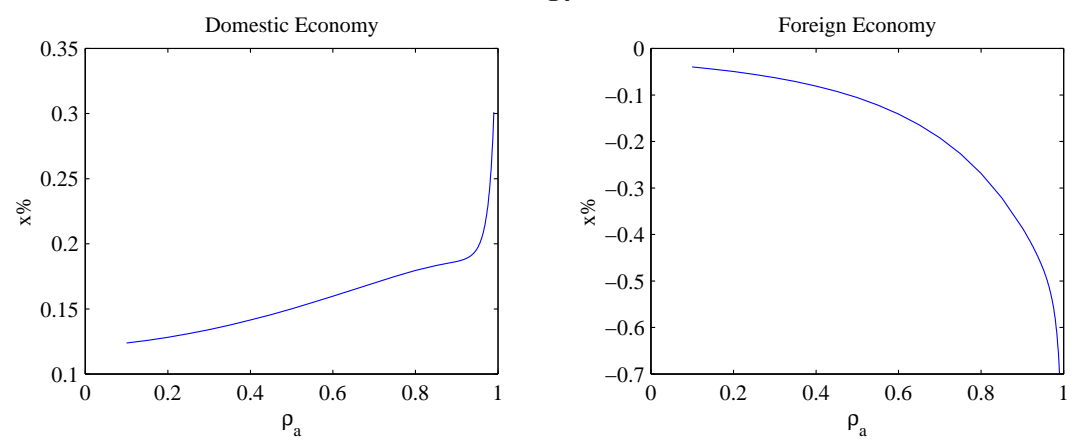

Fiscal shock
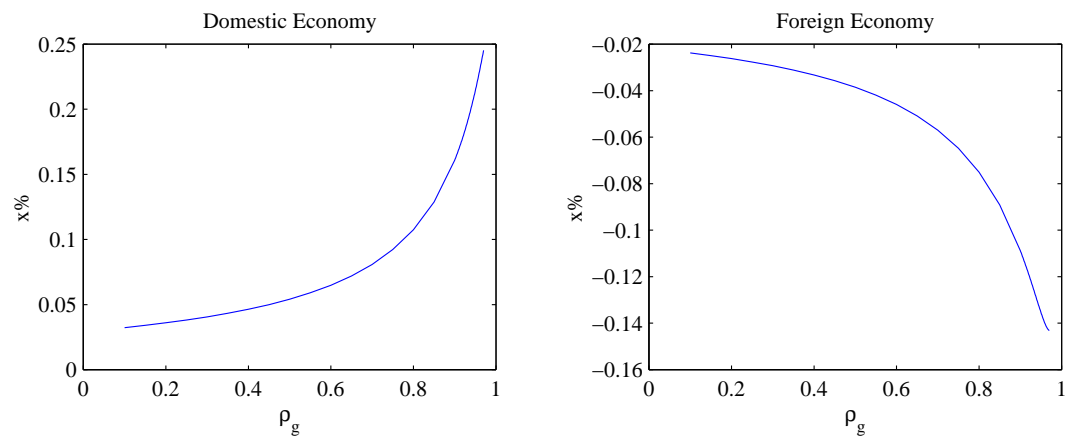

It appears that as the persistence of technological shocks, $\rho_{a}$, decreases, the potential gains from implementing EMU are smaller in the domestic economy, likewise the potential losses in the foreign economy are of much smaller amplitude. This is also true for changes in the level of persistence of fiscal shocks, $\rho_{g}$. This therefore suggest that the more important are intertemporal substitution effects, the lower are the welfare gains/losses from a single currency. A first implication of this result is that the gains and losses associated to the creation of EMU are strongly related to wealth effects, as they are maximized for permanent shocks. This suggests that shutting off the effects of the current account, the gains to EMU would, at least, be smaller as we would bring the size of wealth effects down. Nevertheless, even when shocks display no persistence, the domestic economy still benefits from the shift to a single currency world. So that, even shutting off the current account, we would not totally eliminate the gains to EMU in the domestic economy.

\section{Concluding remarks}

We proposed an intertemporal general equilibrium model of an open economy, in which we introduce nominal rigidities, via prices adjustment costs, and a "pricing-to-market" behavior. We studied the implications of both technology and fiscal shocks on aggregate dynamics in a flexible exchange rate regime as well as in a monetary union.

The analysis of the welfare properties of each exchange rate regime allows us to characterize two important properties of our model under full PTM: 
(i) Implementing EMU is always beneficial to domestic households in face of a positive technology or fiscal domestic shock;

(ii) Conversely, foreign households lose out to the institution of monetary union when a positive shock occurs in the domestic country.

Further, our sensitivity analysis shows that the gains/losses to implementing monetary union are qualitatively robust in face of changes in the degree of nominal rigidities and the elasticity of substitution between foreign and domestic goods. But, our results are quite sensitive to the degree of PTM in the economy. More precisely, it is not worth anymore to implement monetary union (for domestic households) when the LOP holds. It thus appears that both the exchange rate regime and the degree of PTM affects the international transmission of macroeconomic shocks. Finally, changes in the level of persistence of the shocks reveal that these gains and losses are strongly related to the size of the wealth effect, therefore underlining the importance of our assumption of not shutting off the effects of the current account for out analysis of EMU. It would then be interesting to pursue our analysis long the lines of Ghironi [2000] who proposes a model that does not shut off current account, but where non-stationarity are eliminated relying on an OLG structure. It, as suggested in our analysis, the main qualitative results should not be affected, ${ }^{36}$ changes should be expected in quantitative terms, as reducing the wealth effects was found to bring the gains and losses down.

Finally, the literature that deals with optimal currency area often argue that the creation of a single currency area, by lowering the overall volatility, would be welfare enhancing. Our first results seem to validate this argument, but they still have to be confirmed in an explicit stochastic model. This is left for further research.

\section{References}

Backus, D., P. Kehoe, and F. Kydland, International real business cycles, Journal of Political Economy, 1992, 100 (4), 745-775.

_, _ , and _ _ Dynamics of the Trade Balance and the Terms of Trade: The J-Curve?, American Economic Review, March 1994, 84 (1), 84-103.

— $\ldots$, and _ _ International Business Cycle: Theory and Evidence, in Th. Cooley, editor, Frontiers of Business Cycle Research, Princeton University Press, 1995, chapter 11, pp. 331-356.

Ball, L., Policy Rules for Open Economies, Working Paper 6760, N.B.E.R., Cambridge 1999.

Beaudry, P. and M. Devereux, Money and the real exchange rate with sticky prices and increasing returns, Carnegie-Rochester Conference Series on Public Policy, 1995, 43, $55-101$.

\footnotetext{
${ }^{36}$ Further, shocks are usually found to be highly persistent in developed countries, at least as far as technological and fiscal shocks are concerned.
} 
Benigno, G., Real Exchange Rate Persistence with Endogenous Monetary Policy, unpublished manuscript, University of California, Berkeley 1999.

Benigno, P., Optimal Monetary Policy in a Currency Area, unpublished manuscript, Princeton University 1999.

Betts, C. and M. Devereux, The exchange rate in a model of pricing-to-market, The European Economic Review, 1996, 40, 1007-1021.

— and _ Exchange Rate Dynamics in a model of Pricing-to-Market, mimeo, University of British Columbia, Vancouver 1998. Forthcoming in Journal of International Economics.

Blanchard, O.J. and N. Kiyotaki, Monopolistic competition and the effect of aggregate demand, American Economic Review, 1987, 77 (4), 647-666.

Buiter, W., The Economic Case for Monetary Union in the European Union, Review of International Economics, 1997, 5 (4).

Chang, W.Y. and C.C. Lai, The specification of money demand, fiscal policy and exchange rate dynamics, Journal of Macroeconomics, 1997, 19 (1), 79-102.

Chari, V., P. Kehoe, and E. McGrattan, Can sticky price models generate volatile and persistent real exchange rates, Staff Report 223, Federal Reserve Bank of Minneapolis December 1998.

Collard, F. and H. Dellas, Exchange Rate Systems and Macroeconomic Stability, Technical Report, CEPREMAP and University of Bern 2000.

Corsetti, G. and P. Pesenti, Welfare and macroeconomic interdependence, Working Paper 6307, NBER, Cambridge Mass. December 1998.

Devereux, M and C. Engel, Fixed vs. floating exchange rates: How price setting affects the optimal choice of exchange-rate regime, Working paper 6867, NBER, Cambridge, Massachusetts December 1998.

Dornbusch, R., Exchange rates and prices, American Economic Review, 1987, 77, 93-106.

Engel, C and J.H. Rogers, Deviations from Purchasing Power Parity: Causes and Welfare Costs, Mimeo, Iniversity of Washington and Board of Governors of the Federal Reserve System 1999.

Feenstra, R. and J. Kendall, Pass-Through of Exchange Rates and Purchasing Power Parity, Journal of International Economics, 1997, 43, 237-261.

Friedman, M., The case for flexible exchange rates, in Milton Friedman, editor, Essays in positive economics, Chicago: University of Chicago Press, 1953.

Froot, K.A. and P.D. Klemperer, Exchange rate pass-through when market share matters, American Economic Review, 1989, 79, 637-654. 
Ghironi, F., Understanding Interdependence: Do We Really Need to Shut Off the Current Account?, Unpublished Manuscript, Federal Reserve Bank of New-York 2000.

Giovannini, A., Exchange rates and traded goods prices, Journal of International Economics, 1988, 24, 45-68.

Hairault, J.O. and F. Portier, Money, New-Keynesian macroeconomics and the business cycle, The European Economic Review, 1993, 37, 1533-1568.

Hansen, G.D., Technical Progress and Aggregate Fluctuations, Journal of Economic Dynamics and Control, 1997, 21 (6), 1005-1023.

King, R., C. Plosser, and S. Rebelo, Production, Growth and Business Cycles I, Journal of Monetary Economics, 1988, 21 (2/3), 196-232.

Knetter, M.N., An International Comparison of Pricing-to-Market Behaviour, American Economic Review, 1993, 83, 473-486.

Kollmann, R., The exchange rate in a dynamic-optimizing current account model with nominal rigidities: a quantitative investigation, Discussion papers in economics 96-27, University College London, London 1996.

Krugman, P., Pricing to market when the exchange rate changes, in S. Arndt and J.D. Richardson, editors, Real-financial linkages among open economies, Cambridge, Mass.: MIT Press, 1987.

Lane, P., The New Open Economy Macroeconomics: A Survey, Discussion Paper 2115, CEPR 1999.

Loyo, E., Going international with the fiscal theory of the price level, mimeo, Princeton University November 1997.

Lucas, R., Models in Business Cycle, New-York: Basil Blackwell, 1987.

Marston, R., Pricing-to-market in Japanese Manufacturing, Journal of International Economics, 1990, 29, 217-236.

McKinnon, R., Optimum currency areas, American Economic Review, September 1963, 53.

Morrison, C., The cyclical nature of markups in Canadian manufacturing: A production approach, Journal of Applied Econometrics, 1994, 9 (3), 269-282.

Mundell, R., A Theory of Optimal Currency, American Economic Review, 1961, pp. 657-65.

Obstfeld, M. and K. Rogoff, Exchange Rate Dynamics Redux, Journal of Political Economy, 1995, $103(3), 624-660$.

_ and _ Foundations of International Macroeconomics, Cambridge, Massachusetts: MIT Press, 1996.

and __ Risk and exchange rates, Working paper 6694, NBER, Cambridge, Massachusetts 1998. 